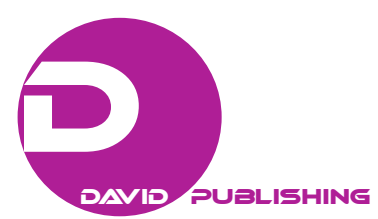

\title{
Research on the Problem of Market Allocation Under the Condition of Asymmetric Information
}

\author{
LIU Songbai \\ Beijing Normal University (Zhu Hai), Zhuhai, China \\ DENG Lan, TENG Limei \\ Beijing Normal University, Beijing, China
}

\begin{abstract}
In contemporary society, the problem of information asymmetry in talent markets has been becoming more prominent. On one hand, the company and candidates fight against each other based on the information available, so both of them could make fraud that will make the market level lower and lower. On the other hand, former scholars have studied from enterprises' perspective and put forward methods to solve it based on the aspect of improving the technology and standard mechanism, which could not solve the problem of information asymmetry thoroughly. Consequently, this research put up with the idea that the market can reduce information asymmetry through the establishing personnel information database and related platforms, which has a great practical significance on realizing the optimal allocation of the market and saving cost. At the same time, this study discussed the problems of information asymmetry fundamentally, which was of great importance to enrich the related theory research. Specific models were constructed through two perspectives from the enterprise and the candidates. And then two models would be eventually integrated into a large system. Finally, this research put all related information into a system, which was beneficial to the optimal allocation of human resources with constraints of the market environment.
\end{abstract}

Keywords: asymmetric information, enterprise, candidates, talent information database, associated platform

\section{Introduction}

Nowadays, the competition among enterprises is diverse including products, market share and so on. However, talent competition is the crucial aspect basically. Therefore, the recruitment of enterprises is particularly important. But in current market, the enterprise and the candidates are caught in a vicious circle: firstly, companies can't recruit the suitable talent in the market, so that managers are not satisfied. Consequently, the final result is that employees will be dismissed. In addition, it's difficult for applicants to find a preferable enterprise to meet their expectations, leading to the large psychological gap, which results in a high employee turnover. These two phenomena have led to the high market liquidity and increased the cost of candidates and enterprises. So, it is a manifestation of the low efficiency of market allocation.

LIU Songbai, professor, International Management, Business School, Beijing Normal University, Zhuhai, China.

DENG Lan, graduate, International Management, Business School, Beijing Normal University, Beijing, China.

TENG Limei, lecturer, Business Management, School of Psychology, Beijing Normal University, Beijing, China.

Correspondence concerning this article should be addressed to DENG Lan, Business School, Beijing Normal University, No. 19, Xinjiekouwai Street, 100875, China. 
Based on the background, several scholars focused on the study of the causes of this phenomenon and how to improve the market allocation efficiency. The study found that information asymmetry is one of the reasons for the phenomenon. Therefore, based on the existing research, this study will research on how to improve the efficiency of market allocation in the context of asymmetric information.

Research on market allocation efficiency under asymmetric information is of great significance for both the enterprise and the applicant. And the ultimate goal is to achieve the optimal allocation of the whole market and to improve the efficiency of the whole market.

\section{Literature Review}

\section{The Information Asymmetry Theory}

The information asymmetry theory was first proposed by Joseph Stiglitz of the Columbia University, Berkeley George Akrylov of California University, and the Stanford University Michael Spence. In 1970, Akerlof (1970) published a paper "The market for lemons: quality, uncertainty and the market mechanism”, which puts forward the idea that the information asymmetry may lead to market "survival of the fittest eliminating”, that is, the market failure. In 1996, Professor James Morris of University of Cambridge and Professor William Vickery of Columbia University proposed asymmetric information theory, who was awarded the Nobel Prize in economics.

Information asymmetry (Monte, 2004) mainly refers to the concept that the seller and the buyer have a certain difference in the information for the market, which means the information sellers master is more complete and buyers have relatively incomplete information. In the talent market, there is a serious problem of information asymmetry between enterprises and candidates. On one hand, enterprises find it difficult to get the true information of candidates. On the other hand, the applicants find it difficult to fully know the situation of enterprises because the way they gather information is very limited.

In the case of asymmetric information, the enterprises are apt to attract more applicants to increase the probability of recruiting competent staff, and candidates are trying to get more opportunities. Both of them are likely to package their information. Impelled by the interest, the enterprise and the candidate can compete fiercely (Liu, 2004). As is seen, both parties have the motivation and the possibility for the fraud.

(1) If both sides do not choose to cheat, companies and candidates will receive five units of benefits.

(2) If companies choose to cheat but candidates not, enterprises will receive eight units of benefits, and the candidate benefit becomes -2. Obviously, the efficiency of enterprises is higher than that of the applicants.

(3) If the candidates choose to cheat while the enterprises not, the applicants will receive eight units of benefits, but the enterprise benefit is negative.

(4) If both sides choose to cheat, then companies will not recruit the suitable staff, while candidates are not satisfied with the enterprise. Consequently, the efficiency of both sides is negative.

However, under the circumstance of information asymmetry, both sides do not know whether the other is cheating, so in order to ensure their own interests, both of them will choose to cheat. Finally, the results would be:

(1) For the enterprise:

Only when companies hired qualified candidates or rejected unqualified applicants will they get better recruitment results. But when the enterprises recruit unqualified employees or reject qualified employees, it will increase the cost of enterprise recruitment and cause the loss of talent resources. Additionally, the recruitment process will become ineffective. 
(2) For the applicant:

Only when the applicants join in the appropriate company or refuse inappropriate company can the decision be effective. But when the applicants join in appropriate company or reject the inappropriate company, the decision cannot be said to be effective. Consequently, talents person will be instable in the market, which is time-consuming.

\section{Relevant Research}

Until now, scholars have focused on the enterprise level, mainly including the following aspects:

Based on the information transmission, it mainly refers to transmission from the dominant position to the inferior position. In general, companies allow more candidates to find detailed information through a variety of ways. Spence (1974) has proposed the signal transmission model firstly. Signal transmission means that first and foremost, enterprises should signal to the applicant showing that they are good companies, which requires enterprises to release recruitment information. What's more, the applicants should be good at capturing the signal, so that they can determine whether their own expectations match with the company. Then they can demonstrate their advantages for the enterprise. At present, since enterprises play the prominent role in the market, Shen (2004) proposed to attract candidates by fully signal transmission which illustrates that it should send a signal to the high-level talents to show it is an ideal university, like participating in the recruitment and media advertising to attract more candidates to come to registration.

Based on the survey on the improvement of technology and technique, that mainly includes the subjective impression of the interviewer as well as the objective of the defects on the means of recruitment methods. Zhang and $\mathrm{Wu}$ (2014) put forward the reason why candidates cannot get real information is their intention as well as the lack of the objective evaluation, including impression management and the interviewer's personal qualities. At the same time, some kinds of methods could be used (Zhang, 2003), and enterprises use different recruitment to overcome difficulties which the information asymmetry brings to the enterprise basing on the stage of development of information technology, including automatic appearance of candidates, credible information signal transmission method, selection of test method, and accumulation position matching method. Besides, the company also needs to make a further study on the organization culture identity when absorbing new staff. Some scholars have put forward from the selection method to collect more public information and private information through certain skills and methods, which contain psychological tests, work samples test, scenario testing, written examination, interview, and other forms to deal with asymmetric information in the recruitment process.

From the perspective of enterprise mechanism, some researchers (He, 2005; Zhu \& Tong, 2006; Gao \& Xiong, 2007) proposed methods to face the condition of asymmetric information, including standardizing recruitment process, establishing a scientific and effective recruitment system, establishing the restriction mechanism, increasing the probability of camouflage and the punishment of camouflage phenomenon, improving information disclosure mechanism, increasing market transparency, establishing the compensation system and etc.

The above researches cannot fundamentally solve the problem even though they have conducted researches through regarding the enterprise as an independent individual. Part of the research is out of the enterprise framework and put forward to strengthen social integrity and moral construction, build integrity and credit evaluation system, establish and improve the talent pool, and standardize intermediary institutions (Lv, 
2014; Wang, 2015; Ji, 2006). However, these studies did not describe how to carry on the practice in the market.

\section{Model Construction}

\section{Business Perspective-Cooperative Relationship Among the Relevant Institutions to Share Resources}

After the interview of candidates, their information will be added into enterprise personnel information database. It includes the candidates' work experience, education level, skill level, and other information. And when the enterprise demand and the applicant showed a high degree of consistency, the enterprise will contact the applicant to ask its inaugural intention, which is a traditional practice. By this way, enterprises have more chances to get more human resources. However, the entire process takes too much time and the uncertainty is too high (during this time this candidate may have found other jobs). Besides, independence of each enterprise in the human resources information is the cause of fault information. A candidate in enterprise A shows a high degree of consistency with B, but B doesn't have the applicant's information. So the B is likely to continue its recruitment or recruit an employee who is hardly to meet its requirement. The applicants may continue to seek job opportunities in the market or join in inappropriate businesses so that the cost will increase. Therefore, the final result is a waste of market resources.

To establish a talent pool in the entire talent market, it is necessary to link the relevant agencies to the shared information resources among them. Finally the enterprise can recruit the right staff.

\section{Establishing the General Talent Information Database}

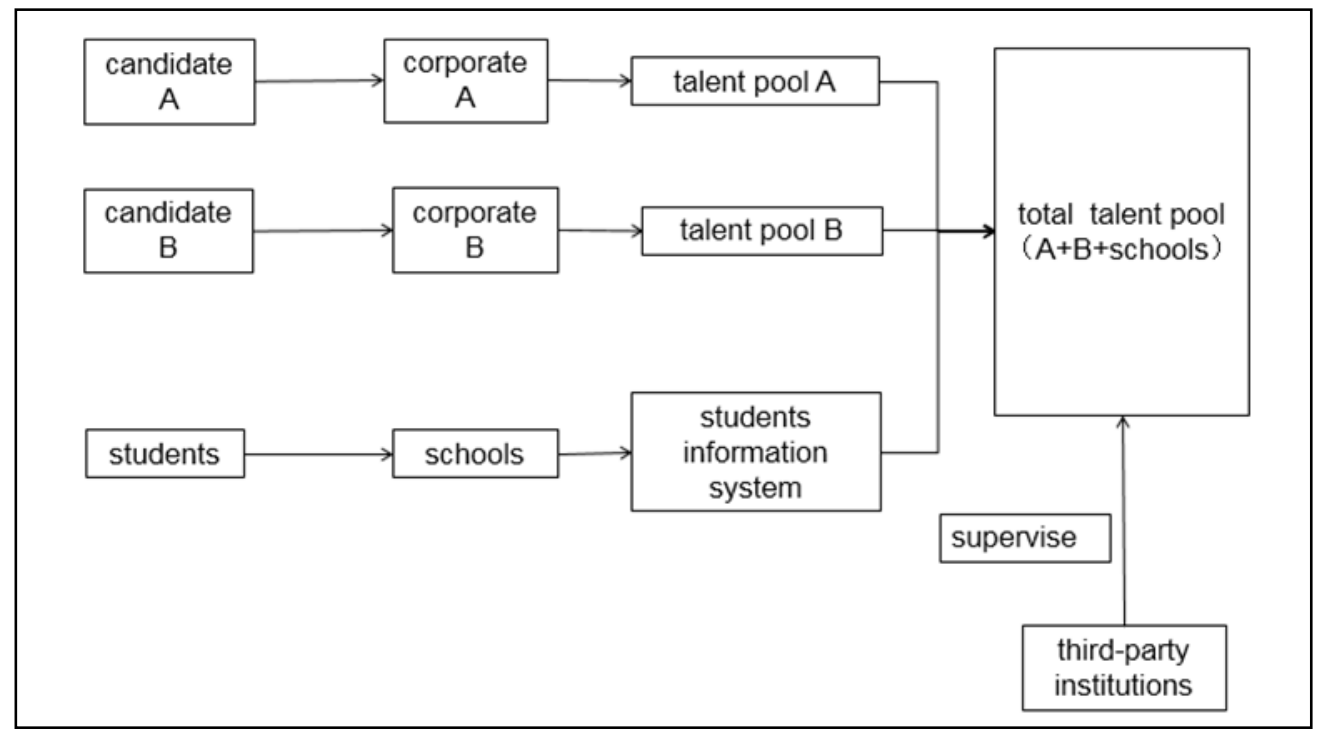

Figure 1. The model of total information database of talent.

As shown in Figure 1, in the model, this research proposed to put the personnel information database of all enterprises together. Because college students will be added to the market force later, this model will also contain students' information system.

The information database of the total talents includes the background experience, job performance, the moral behavior, and the relationship between the talents. The general talent information database is integrated into the basis of each enterprise to build its own talent pool. The basic idea of the model is to achieve the 
sharing of resources, once the candidates begin to enter the talent market. Even during the period of a student, the candidate's information is beginning to be market records.

One thing that needs to be noticed is that information disclosure is one of the main problems in the information age. Therefore, if you do not have a good security measure, this theory is difficult to achieve. In the model, the third party organization (can be the government or other formal intermediary organizations) is added to supervise the total personnel information database.

\section{The Operating Mechanism of Enterprises in the Interview Process}

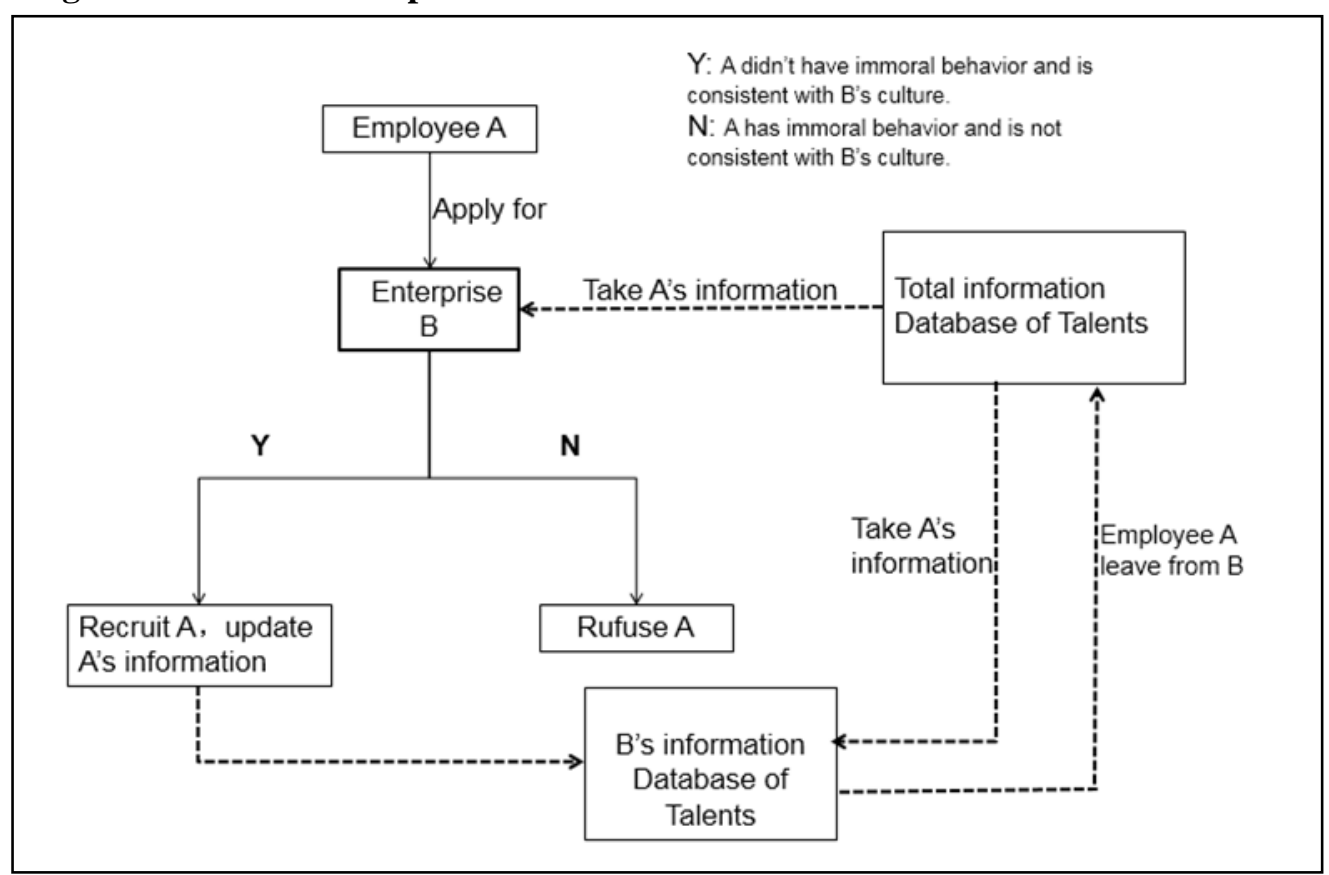

Figure 2. The process of seeking for a job.

As shown in Figure 2, specifically, it can be seen how a single enterprise uses the total personnel information database to complete the recruitment process: this research assumed that employee A leaves from enterprise $\mathrm{A}$ and then seeks for enterprise $\mathrm{B}$. This process can be divided into the following three stages:

The first stage: employee leaves from A, and then his information begins to flow into the total personnel information database.

The second stage: employee seeks for enterprise B, including following main assessment:

(1) The routine examination process, including the written examination and interview, mainly inspects the basic quality and ability of the staff. If it meets the company's requirements, then go ahead; if not, quit it.

(2) After the consent of the employee, B can take the relevant information from the total personnel information database to check the employee's background and experience or other soft capacity assessment. In general, the candidates will agree the enterprise requirement to call information; if they do not agree, maybe interviewers need to consider whether there is something they are hiding and then decide whether to conduct further examination.

(3) The purpose of decision-making is to employ the staff or not. After reviewing the relevant information, if the employee does not exhibit unethical behavior in the previous work and their personality is consistent with the enterprise's culture, making hiring decisions and transferring the staff information from the general 
information base to the company's internal information database are vital for them to update follow-up information of staff in the company internal database. Conversely, if it shows immoral behavior in previous work or there are differences between past performance and interview performance, the hiring decision would not be made.

The third stage: the staff leaves from enterprise B. At this stage, the information of the staff in the company B will not update. B will return the information to the total information database so that other companies can obtain the information.

In the model, the total talent information database and the enterprise combine to play the role of constraints. According to the personnel information database, enterprises obtain the information to make a complete evaluation on the candidates because the information database has recorded the events of the past. So candidates must pay attention to their demeanor and avoiding immoral behavior. Through this way candidates could avoid the loss caused by immoral behavior of candidates.

\section{Candidates Perspective}

Because of the information asymmetry, candidates cannot obtain information timely. So the enterprises do not know whether it is in line with their own demands. Based on this theory, this study proposed to establish an association platform to achieve the matching between the applicant and the enterprise (see Figure 3).

The associated platform is similar to the current recruitment website, but the difference is that the former utilizes the mature scale for the assessment. Enterprises are assessed by employees, customers, other businesses, and stakeholder. Finally, the third party matches the enterprises with the candidate characteristics. Once the degree of match reaches to a certain extent, the platform can recommend appropriate candidates or enterprises to each other.

Once the platform is built, it will play the role of constraints in the market for both sides: candidates will choose to be honest when taking into account the time cost for job opportunities. What's more, enterprises will do the same in order to obtain a good evaluation and appropriate personnel in the evaluation system. In the long run, this approach improves the timeliness of recruitment and saves costs.

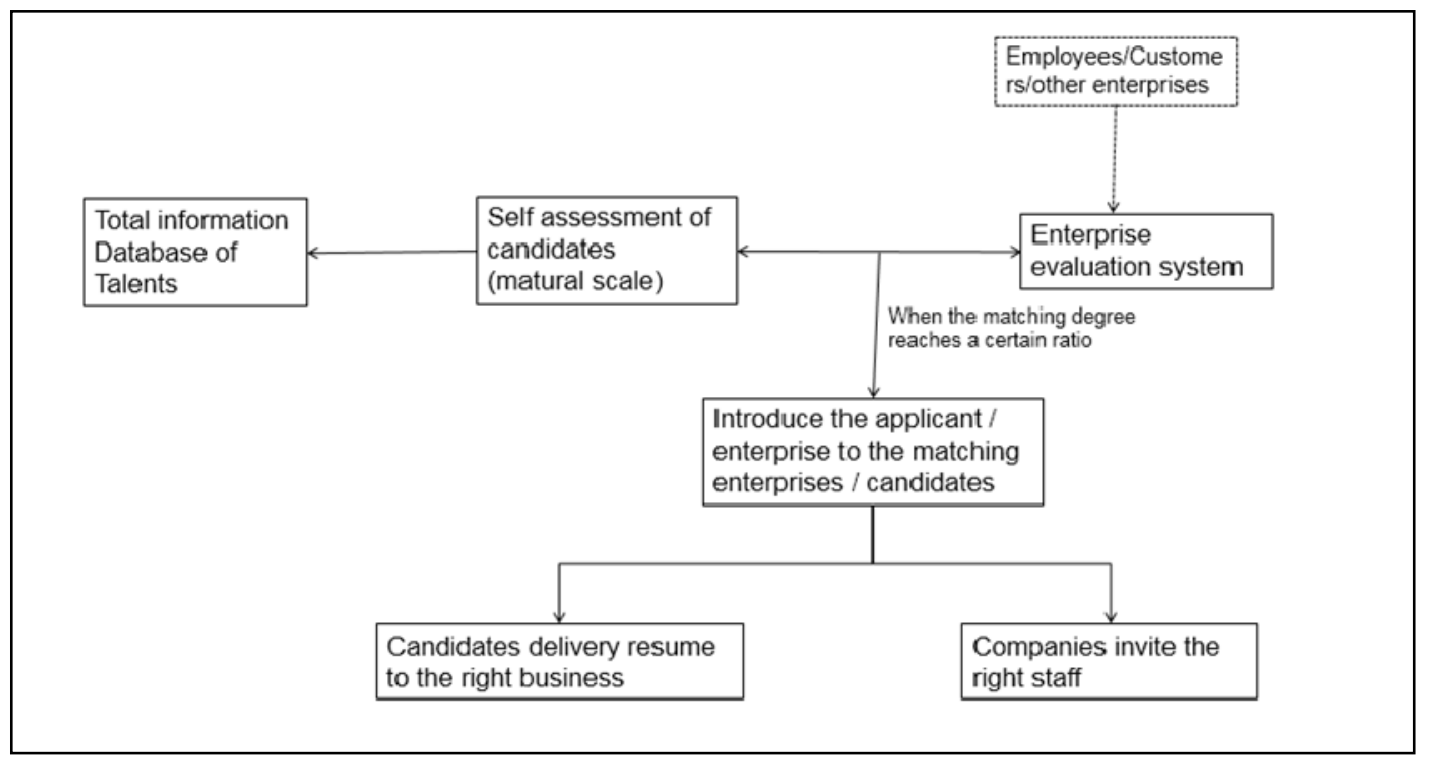

Figure 3. Model of associated platform. 


\section{Summary}

As shown in Figure 4, the final talent database contains not only the candidate's work experience and skills, but also the candidate's personality trait information through self-rating. Through the talent information database, it can establish a relationship between the enterprise and the applicant.

At present, some areas have started the exploration and practice. In Beijing, Shanghai, and other cities, tremendous number of companies began to constantly improve the talent credit archives. Chinese Talent Credit Union, established in Guangzhou, sponsored by several well-known domestic enterprises also pointed out: union enterprise will record the core position, the integrity of core staff objectively and truthfully and archive form of registration in the internal web site. When the employees want to leave, other alliance enterprises can know the integrity evaluation by the integrity files of the employee to prevent false qualifications, false performance, or leakage of the original enterprise secret. In addition, the recruitment of core employees, mainly through the "the file of integrity", can understand the loyal records of the staff. All of these proofs provide a certain convenience for the recruitment of enterprises.

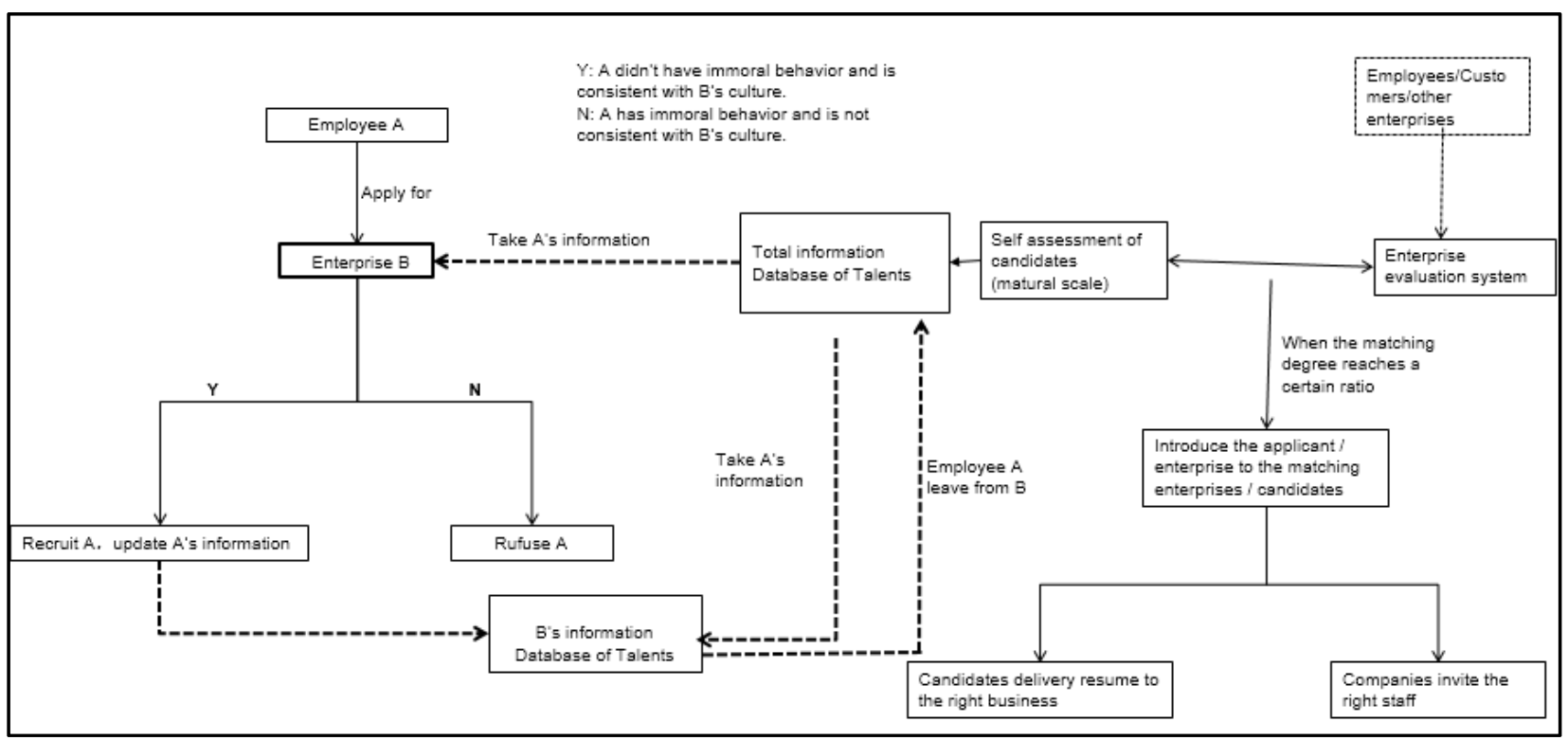

Figure 4. The whole process.

\section{Conclusions}

At the beginning of the establishment of the model, enterprises need to invest tremendous manpower, material resources, financial resources, etc. So in the short term, the cost of enterprises will increase undoubtedly. But in the long run, it is of great significance for the long-term development of the enterprise and the effective operation of the market.

The system premise of the construction for this model is a perfect punishment and supervision mechanism. This mechanism is mainly for enterprise managers and executives, who are mainly responsible for staff assessment. And the main influencing factors are also from that. From this perspective, the authenticity of the information is vulnerable to doubt. Therefore, it is necessary to establish the mechanism of punishment and supervision for senior executives exteriorly. They ought to take responsibility for their behavior. Therefore, if their decisions do not match with the facts of the evaluation, they will be punished. So, in order to avoid being 
punished, they will be more inclined to make a real and objective evaluation.

In addition, besides some non-standard small enterprises in China, it will be difficult to integrate them into the system to a certain degree. Therefore, the market should be normalized for establishing desirable market circumstance.

In a word, this research mainly put forward a hypothesis model, which needs to be tested and perfected to develop into a mature theoretical system.

\section{References}

Akerlof, G. (1970). The market for "lemons": Quality uncertainty and the market mechanism. Quarterly Journal of Economics, (84), 488-500.

Spence, M. (1974). Competitive and optimal responses to signals: An analysis of efficiency and distribution. Journal of Economic Theory, 7(3), 296-332.

Gao, Y., \& Xiong, Y. (2007). How to improve the effectiveness of corporate recruitment: Analysis based on information asymmetry. Inner Mongolia Science Technology \& Economy, (141), 57-63.

He, H.-T. (2005). Analysis about the risk of recruitment under information asymmetry. Sci-technology and Management, (6), 47-49.

Ji, X.-Y. (2006). Information asymmetry and perfection in graduates' job market. Popular Science \& Technology, (3), $180-181$.

Monte, C. (2004). Fame theory \& economics. Beijing: Economic Management Press.

Lv, P.-J. (2014). Research on corporate HRM based on information asymmetry. Hebei Corporate, (5), 80-82.

Liu, L. (2004). Game theory during recruitment of enterprises. Journal of Hebei Institute of Technology (Social Science Edition), (5), 74.

Shen, J.-M. (2004). The problem of information non-symmetry in universities' employment and its countermeasures. Journal of Ningbo University (Educational Science), (4), 72-74.

Wang, Q. (2015). How to improve the effectiveness of corporate recruitment under the condition of information asymmetry. RrnCaiZiYuanKaiFa, (6), 47.

Wang, Y.-C., \& Wu, H.-H. (2014). Research on information asymmetry in interview. Modern Business Trade Industry, (11), 114-116.

Zhang, P.-D. (2003). On correction strategy for information asymmetry in personnel employment. Journal of Shanghai University (Social Science Edition), (4), 95-102.

Zhu, J., \& Tong, X.-Y. (2006). Human resources recruiting based on theory of information asymmetry. Journal of Hangzhou Teachers College (Natural Sciences Edition), (3), 161-163. 